\title{
Molecular phylogenetics reveal multiple tertiary vicariance origins of the African rain forest trees
}

\author{
Thomas LP Couvreur*1,3, Lars W Chatrou ${ }^{1}$, Marc SM Sosef ${ }^{1}$ and \\ James E Richardson ${ }^{2}$
}

Address: ${ }^{1}$ Nationaal Herbarium Nederland, Wageningen branch, Biosystematics Group, Wageningen University, 6703 BL, Wageningen, The Netherlands, ${ }^{2}$ Royal Botanic Garden Edinburgh, Edinburgh, EH3 5LR, UK and ${ }^{3}$ The New York Botanical Garden, Bronx, NY, 10458-5126, USA

Email: Thomas LP Couvreur* - tcouvreur@nybg.org; Lars W Chatrou - Lars.Chatrou@wur.nl; Marc SM Sosef - Marc.Sosef@wur.nl; James E Richardson - J.Richardson@rbge.ac.uk

* Corresponding author

Published: 16 December 2008

BMC Biology 2008, 6:54 doi:10.1186/1741-7007-6-54
Received: 20 June 2008

Accepted: 16 December 2008

This article is available from: http://www.biomedcentral.com/174I-7007/6/54

(C) 2008 Couvreur et al; licensee BioMed Central Ltd.

This is an Open Access article distributed under the terms of the Creative Commons Attribution License (http://creativecommons.org/licenses/by/2.0), which permits unrestricted use, distribution, and reproduction in any medium, provided the original work is properly cited.

\begin{abstract}
Background: Tropical rain forests are the most diverse terrestrial ecosystems on the planet. How this diversity evolved remains largely unexplained. In Africa, rain forests are situated in two geographically isolated regions: the West-Central Guineo-Congolian region and the coastal and montane regions of East Africa. These regions have strong floristic affinities with each other, suggesting a former connection via an Eocene pan-African rain forest. High levels of endemism observed in both regions have been hypothesized to be the result of either I) a single break-up followed by a long isolation or 2) multiple fragmentation and reconnection since the Oligocene. To test these hypotheses the evolutionary history of endemic taxa within a rain forest restricted African lineage of the plant family Annonaceae was studied. Molecular phylogenies and divergence dates were estimated using a Bayesian relaxed uncorrelated molecular clock assumption accounting for both calibration and phylogenetic uncertainties.
\end{abstract}

Results: Our results provide strong evidence that East African endemic lineages of Annonaceae have multiple origins dated to significantly different times spanning the Oligocene and Miocene epochs. Moreover, these successive origins (c. 33, 16 and 8 million years - Myr) coincide with known periods of aridification and geological activity in Africa that would have recurrently isolated the Guineo-Congolian rain forest from the East African one. All East African taxa were found to have diversified prior to Pleistocene times.

Conclusion: Molecular phylogenetic dating analyses of this large pan-African clade of Annonaceae unravels an interesting pattern of diversification for rain forest restricted trees co-occurring in West/Central and East African rain forests. Our results suggest that repeated reconnections between the West/Central and East African rain forest blocks allowed for biotic exchange while the break-ups induced speciation via vicariance, enhancing the levels of endemicity. These results provide an explanation for present day distribution patterns and origins of endemicity for African rain forest trees. Moreover, given the pre-Pleistocene origins of all the studied endemic East African genera and species, these results also offer important insights for setting conservation priorities in these highly diversified but threatened ecosystems. 


\section{Background}

Tropical rain forests harbor outstanding levels of biodiversity. Numerous studies have focused on how such high levels of species richness might be maintained through time [1-3]. Much less is known about the evolutionary origins that have led to the generation of these hyper-rich ecosystems [4,5]. Understanding the evolutionary history and biogeographic processes behind the origin of such areas plays a central role in setting conservation priorities $[6,7]$. In Africa, rain forests of the Guineo-Congolian floristic region [8] occur in a coastal band in West Africa and occupy vast areas in Central Africa (Figure 1A). In East Africa, rain forests occur in small, highly fragmented patches near the coast and in the adjacent Eastern Arc Mountains (Figure 1A), covering a small surface area (c. $7000 \mathrm{~km}^{2}$ ). Despite the relatively small size of the area the East African rain forests harbor an exceptional density of endemic plant species $[9,10]$, which is one of the highest on the planet [7], and have been identified as one of 25 global biodiversity hotspots [7]. The Guineo-Congolian and East African regions are geographically isolated by a c. $1000 \mathrm{~km}$-wide North-South arid corridor creating an effective barrier to dispersal for rain forest-restricted taxa. Nevertheless, floristic comparisons indicate strong affinities between the two rain forest regions within numerous distantly related plant families $[8,9,11,12]$. Indeed, many endemic species are representatives of widespread genera co-occurring in the Guineo-Congolian and East African rain forest regions. In addition, the endemic East African genera are thought to be closely related to Guineo-Congolian genera. These strong affinities are gen-

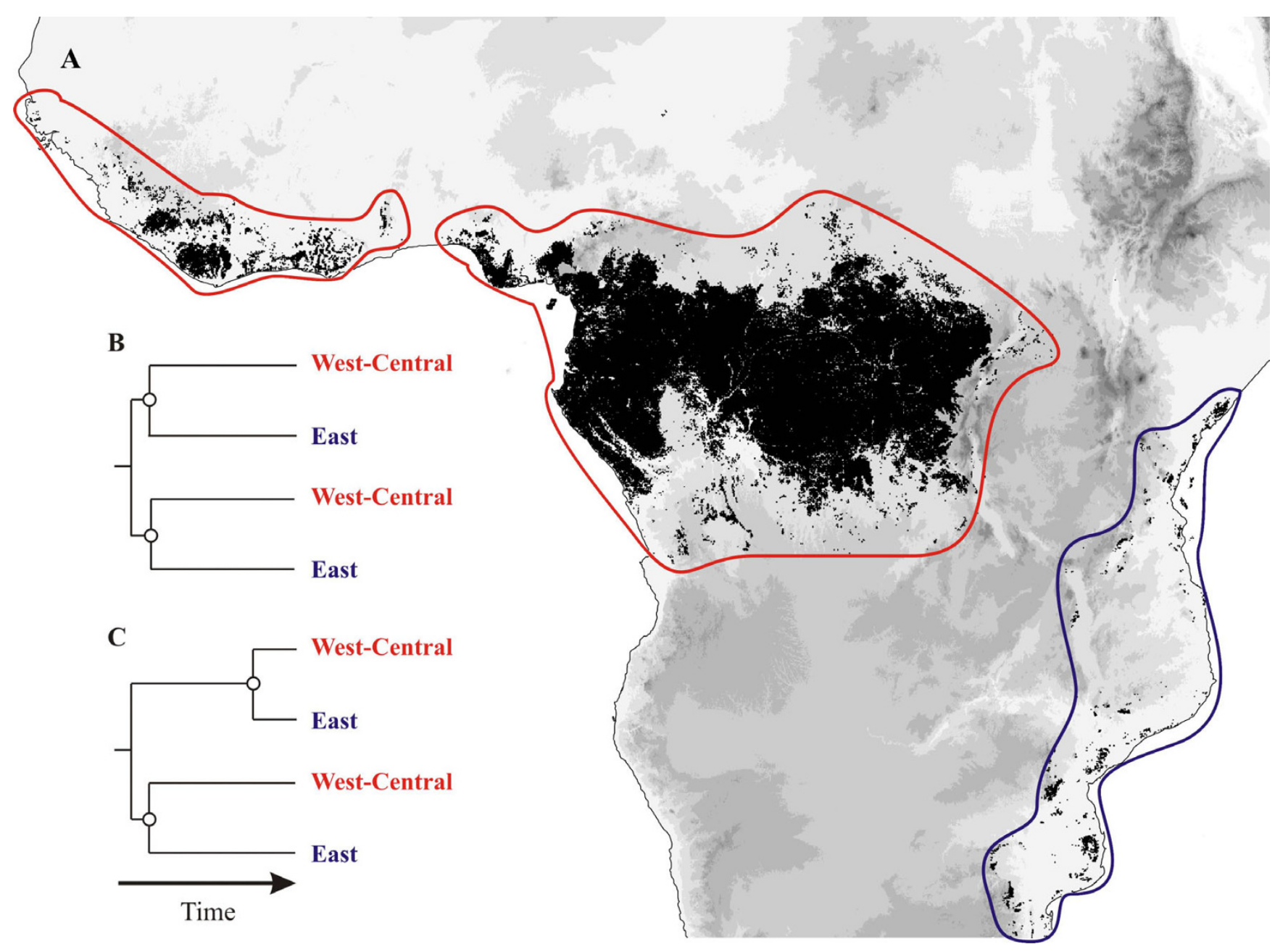

Figure I

Alternative hypotheses of African rain forest origins. (A) Distribution of lowland rain forest in Africa (black) overlaid by altitudinal range (increasing altitude with darker grey). Red lines highlight the Guineo-Congolian region; the blue line highlights the East African region. (B) Phylogenetic tree expected from a single break-up scenario. (C) Phylogenetic tree expected from multiple break-ups at significantly different times scenario. Open circles indicate West-Central/East splits. 
erally explained by the presence of a continuous rain forest across tropical Africa during the Eocene [9-16].

One hypothesis for explaining the high levels of endemicity suggests that this pan-African rain forest broke up only once at the onset of East African aridification during the Oligocene-Early Miocene (c. 33-20 Myr) [11-13,15,17] and that the c. $30 \mathrm{Myr}$ of isolation of the East African rain forests coupled with a highly fragmented habitat led to the high levels of endemicity observed in East Africa. In contrast, an alternative hypothesis suggests that from the mid-Tertiary onwards (c. 33-2 Myr) African rain forests expanded and contracted on multiple occasions after the initial break-up $[9,12,14,16]$. Expansion and reconnection would have allowed new lineages to spread from West-Central Africa to East Africa or vice versa. Subsequent contraction and isolation would have resulted in diversification by vicariance or allopatric speciation, thus enhancing the levels of biodiversity and endemicity.

In the context of studying the origins of East African dryadapted endemic species in the genus Acridocarpus (Malpighiaceae), dated molecular phylogenies have proven to be a powerful tool [17]. Here we use a similar approach on a rain forest-restricted clade with disjunct West-Central and East African distributions, which provides a way to test the above hypotheses. If a single break-up of the panAfrican rain forest is responsible for the observed distribution, then all the splits between Guineo-Congolian and East African lineages should be dated to the same period (Figure 1B). In contrast, in an oscillating forest scenario we expect to find a chronological sequence of multiple vicariance events, with splits dated at significantly different time periods (Figure 1C).

We studied the evolutionary history of the largest monophyletic African clade of rain forest trees [18] within the diverse pan-tropical family Annonaceae. Annonaceae is one of the best examples of a tropical plant family for which strong positive correlations were found between abundance and species richness, and temperature and rainfall, respectively [see [19]]). This implies that Annonaceae are mainly restricted to tropical rain forests and thus provide an ideal model family to test hypotheses on the evolution of rain forests. The studied African clade is composed of three genera endemic to the East African rain forests, two endemic to the Guineo-Congolian region, and six disjunct genera with numerous species endemic to either East or West-Central African rain forests [20]. These genera are not found in arid parts of Africa and are restricted to forests with high rainfall regimes and relatively short dry seasons. Moreover, the comparatively large fruits found within this group are not adapted to long-distance dispersal. Within this clade, monocarps are sessile in genera with apocarpous fruits [18] and differ from the stalked monocarps that are more common in Annonaceae. So, even though individual fruitlets are free, in the context of dispersal these genera have fruits that functionally are equivalent to syncarpous fruits, far too large for effective long-distance dispersers such as birds. Rather, they are dispersed by mammals that are restricted to rain forests, such as gorillas [21], and their crossing wide arid corridors is a highly improbable event. This low dispersal capacity as well as the restriction and abundance of this clade in both the Guineo-Congolian and East African rain forests $[11,20,22]$ renders this clade suitable for testing the above hypotheses.

Two dated, well-resolved molecular phylogenies were generated using plastid DNA sequences, focusing specifically on two different taxonomic levels within the African clade. The first phylogeny contained representatives of all eleven African genera and was used to date the deeper splits within this clade. Second, a species-level phylogeny was estimated for two sister genera, Isolona and Monodora, each of which has endemics in both Guineo-Congolian and East African rain forests $[20,23]$. Both trees were dated under a Bayesian relaxed uncorrelated molecular clock assumption.

\section{Methods \\ Taxon sampling and sequence data}

For this study two different chloroplast DNA sequence datasets were used. First, in order to date the origin of the East African endemic genera, a previously published DNA sequence data matrix (dataset $\mathrm{A}$ in Additional file 1) of the African clade was used (Couvreur et al., 2008, treeBASE SN3554). This dataset, totaling 64 taxa, included all the genera of the African clade (11 genera) and presented a thorough sampling of the genera within the long branch clade [24]. The family Eupomatiaceae was used as the outgroup [Eupomatiaceae has been recovered as sister to Annonaceae, $[25,26]])$. The dataset was composed of six plastid markers, three non-coding ( $\operatorname{trn} L-\operatorname{trn} F, \operatorname{trnSG}$, and $p s b A-\operatorname{trn} H)$ and three coding $(n d h F, r b c L$, and partial matK), totaling 7945 characters.

Second, in order to date the splits within genera, a specieslevel phylogeny of the two sister genera Isolona (15 out of 20 species) and Monodora (13 out of 14 species) was generated (dataset B, see Additional file 1, treeBASE number SN3633). For both genera all the known East African species were included.

A modified cetyl trimethyl ammonium bromide (CTAB) protocol of Doyle and Doyle [27] following Bakker et al. [28] was used for DNA extraction. The universal primers $\mathrm{C} / \mathrm{D}$ and $\mathrm{E} / \mathrm{F}[29]$ were used to amplify and sequence the trnL intron and trnL-trnF spacer. The psbA-trnH intergenic spacer was amplified and sequenced using primers $p s b A$ 
and $\operatorname{trnH}$ (GUG) [30]. The trnS-trnG intergenic spacer was amplified and sequenced using primers trnS (GCU) and trnG (UCC) [30] and the trnD-trnT marker was also amplified and sequenced using primers trnTGGU and trnDGUC [31]. In addition, the second part of the $n d h F$ gene was sequenced as it has been shown to be more variable than the more conserved 5 ' region and is thus more appropriate for species-level analyses [32]. The Annonaceae specific primer LBC-intF [32] was used in combination with the usual 2110R primer [33] amplifying a region of c. 620 bp. PCR reactions were performed with 30-50 ng of genomic DNA, $0.4 \%$ of BSA, $0.2 \mu \mathrm{M}$ of each primer, 0.2 $\mathrm{mM}$ dNTP PCR mix (Promega, Madison, WI), $3 \mu \mathrm{M}$ $\mathrm{MgCl}_{2}, 1 \times$ PCR buffer (Promega, Madison, WI), and $0.5 \mathrm{U}$ of Taq DNApolymerase (Promega, Madison, WI) in a total volume of $50 \mu \mathrm{l}$. The PCR program was as follows: 35 thermal cycles at $94^{\circ} \mathrm{C}$ for 1 minute, $50-55^{\circ} \mathrm{C}$ for 50 seconds, $72^{\circ} \mathrm{C}$ for 50 seconds and a final extension at $72^{\circ} \mathrm{C}$ for 3 minutes.

For both datasets, sequences were edited using the program Staden [34] and aligned manually using PAUP* [version 4.10b; [34]]. Gaps were coded following the simple coding model of Simmons and Ochoterena [35]. Microsatellites were excluded from the analysis, as these structures probably originate through slipped-strand mispairing [36] and are likely to be highly homoplasious.

\section{Phylogenetic analysis and divergence date estimates}

In order to test whether the estimated dates of the origin of the East African endemic lineages are significantly different the molecular trees were dated under a Bayesian framework using the software BEAST v. 1.4.7 $[37,38]$. The method implemented in BEAST simultaneously estimates divergence times, tree topology, and rates, thereby providing a clear advantage over previous relaxed clock methods [39] that estimate tree topology and divergence dates separately [e.g. [40-42]]). Both datasets were partitioned into the number of markers used by directly editing of the XLM file and following Couvreur [44]. The best performing evolutionary model for each marker was identified under two different model selection criteria, the hierarchical likelihood ratio test (hLRT) and the Akaike information criterion [AIC; [43]]) as implemented in MrModelTest [44]. For both datasets two independent analyses were undertaken to check for convergence of the MCMC chains. Analyses were undertaken by sampling every 1000 th generation, and were considered complete once the effective sampling size (ESS) of each parameter was above 200, as suggested in the BEAST manual. In order to assess that the MCMC chain reached stationarity we examined the lnL plots using Tracer v. 1.3 [45]. In particular, we searched for evidence that the model likelihood and parameter estimates had reached stationarity after a burnin period.

\section{Calibration}

The testing of the two alternative hypotheses presented in Figure 1 can be viewed under a relative time scale [46], i.e. with no reference to any absolute timing. However, fossil information is available and was used in order to calibrate trees in an absolute time frame. The fossil taxon Archaeanthus [98 Myr, [47]]) is characterized by distinctive derived stipules, an elongated receptacle, and fruits with numerous well spaced follicles, all of which are interpreted as synapomorphies shared with the family Magnoliaceae [47-49]. Thus, this fossil provides a minimum age for the stem of Magnoliaceae of 98 Myr. Even though the correct placement of this fossil within the Magnoliales has been questioned in the past [50], recent studies [24,48,51] have largely relied on Archaeanthus to date this family. Fossil information within Annonaceae is limited ([e.g. [52,53]]) and is thought $[24,48]$ to be unreliable with respect to their exact placement and was thus not used in this study. One other relevant fossil is the Early Cretaceous Endressinia taxon (112 Myr [56]). This fossil is characterized by broad staminodes with lateral glands, which implies a possible sister relationship to Eupomatiaceae and would thus provide an older minimum age of 112 Myr for the split between Eupomatiaceae and Annonaceae than with Archaeanthus. However, the method used to assign Endressinia to Eupomatiaceae (see [57]) has been criticized and is thought to be unreliable [58]. Thus, we deemed Archaeanthus the most reliable fossil calibration point and this was used to assign a minimum age to the Magnoliaceae stem node.

Using the age of Archaeanthus as well as a wider taxon sampling within Annonaceae (80 genera out of c. 110, 205 OTUs) and rbcL and trnLF sequences, Pirie [59] provided an age estimate of $91 \mathrm{Myr}( \pm 1.5 \mathrm{Myr})$ for the stem of Annonaceae (split between Eupomatiaceae and Annonaceae) when using the Penalized Likelihood method of Sanderson [43]. This estimated date is in accordance with previously published date estimates for the origin of Annonaceae [24,60]. Thus, 91 Myr was used as a calibration point for dataset A. Secondary calibration (calibrating a node with a date provided by a previous analysis) is a commonly used alternative given the absence of a method for direct calibration (e.g. fossil or geological [61-63]). However, it has been shown that, unless particular care is taken, secondary calibration can generate internal inconsistencies leading to unreliable dates [64]. BEAST accommodates for calibration uncertainty by applying a prior probability distribution on the age, e.g. a prior distribution defined in terms of its mean and standard deviation [38]. A wide variety of prior probability distributions are available [65]. For this study a normal probability distribution was used as it is thought to better reflect uncertainty related to secondary calibration points [65]. For dataset A, a mean of 91 and a stand- 
ard deviation of 1.5 were specified. This effectively encloses a range of possible ages from c. 89 to 93 Myr. In dataset $\mathrm{B}$, a normal distribution was also used for the age of the stem node of Isolona and Monodora, with the mean taken from the analysis of dataset A. The standard deviation was set to contain the lower and higher boundaries of the $95 \%$ highest posterior density values effectively accommodating for age uncertainty.

Both sequence datasets (A and B) deviated from a strict molecular clock and rates between adjacent branches were uncorrelated as shown by the values of the parameters 'coefficient of variation' and 'covariance', respectively [66] (Table 1). Thus divergence times were estimated under a lognormal non-correlated relaxed clock method and using the Yule model of speciation as implemented in BEAST 1.4.7. In all cases user-specified chronogram trees were used as starting trees and were obtained using the r8s program [67]. Finally, taxon subsets were specified for each clade of interest allowing recording of the mean time of the most recent common ancestor $\left(t_{\mathrm{MRCA}}\right)$, the $95 \%$ highest posterior density intervals (HPD), and the effective sampling size (ESS). Dates were considered significantly different only when the 95\% HPDs were not overlapping.

\section{Results}

\section{Divergence times}

Our results provide strong support for the multiple connection-reconnection hypothesis with relative ages of splits occurring at three significantly different periods in time (Figure 2). The estimated absolute ages for all of the major clades recognized within Annonaceae are in perfect agreement with recent studies $[24,50]$. Within the African clade five different origins of endemic East African lineages were identified (Figure 2A and 2B, nodes a-e). Node ' $a$ ' represents the origin of the Sanrafaelia/Ophrypetalum clade with a mean age of 32.9 Myr (95\% HPD: 42.9-23.6 Myr) and node ' $b$ ' that of Asteranthe with a mean age of 16.8 (HPD: 23.4-10.5). Node ' $\mathrm{C}$ ' indicates the origin of the East African endemic species Uvariodendron kirkii, with a mean of 8.4 Myr (HPD: 13.2-3.7). Two further nodes are indicated in Figure 2B, with the first one corresponding to the origin of the East African species of Monodora (node ' $\mathrm{d}$ '), with a mean of $8.4 \mathrm{Myr}$ (HPD: 12.2-4.7). The lack of phylogenetic resolution makes it impossible to distinguish the origin of the East African species of Isolona (Figure 2B). Therefore, only a minimum age for this potential split can be provided corresponding to node ' $e$ ' with a mean of 5.4 Myr (HPD: 8.4-2.5). Each age estimate (Figure 2C) for these nodes is dated to three significantly different periods of time as the 95\% HPDs do not overlap. For node 'c', 'd', and ' $e$ ' the 95\% HPDs do largely overlap, indicating no significant differences in the age estimates.

\section{Phylogenetic analyses}

The chronograms and phylogenetic relationships resulting from both analyses are presented in Figure 2A and 2B. At the generic level (dataset $\mathrm{A}$ ) the resulting phylogenetic relationships as well as corresponding branch support were identical to those found in Couvreur et al. [18]. The species-level chronogram (dataset B) of the two sister genera Isolona and Monodora is represented in Figure 2B. Monodora has two well-supported sister clades (Bayesian posterior probability $-P P=1.00)$ : a West African clade, and an East African clade. Relationships within the West African clade are weakly supported except for the sister position of Monodora angolensis $(P P=1.00)$ to the remaining West African species. In the East African clade, Monodora grandidieri is strongly supported as sister to the rest of the taxa. Moreover, Monodora globiflora with Monodora carolinae and Monodora stenopetala, as well as Monodora hastipetala with Monodora junodii form well-supported subclades $(P P=1.00)$. The Malagasy species of Isolona form a highly supported, nested clade. The East African taxa are also strongly supported as nested within Isolona; however, their relationship with the other clades remains unresolved.

\section{Discussion}

Our results demonstrate that the splits between the Guineo-Congolian and East African Annonaceae lineages have multiple origins at significantly different times (Figure 2), which is congruent with the hypothesis presented in Figure 1C. Given that the majority of species found within this clade are restricted to rain forests and present no long-range dispersal potential, we interpret the observed pattern as a likely consequence of a series of con-

Table I: Mean and $95 \%$ of the highest posterior distributions (HPD) of the coefficient of variation and covariance parameters for dataset A (genus-level phylogeny) and B (species-level phylogeny)

\begin{tabular}{lll}
\hline & Coefficient of variation & Covariance \\
\hline Mean dataset A (30 million generations, sampled every 1000th) & $\mathbf{0 . 5 2 5}$ & $\mathbf{7 . 3 3 E - 0 2}$ \\
95\% HPD lower & 0.45 & -0.101 \\
95\% HPD upper & 0.602 & 0.238 \\
Mean dataset B (5 million generations, sampled every 1000th) & $\mathbf{0 . 7 5 3}$ & $\mathbf{- 4 . 5 2 E - 0 2}$ \\
95\% HPD lower & 0.521 & -0.254 \\
$95 \%$ HPD upper & 1.012 & 0.186
\end{tabular}


C

e: 5.4 Myr (8.4-2.5)

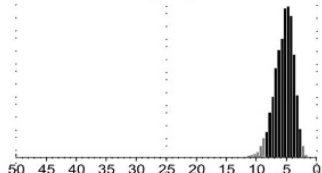

d: 8.4 Myr (12.2-4.7)

c: 8.4 Myr (13.2-3.7)

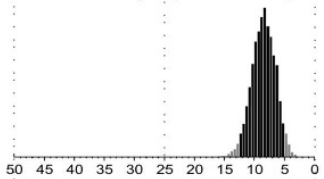

b: 16.8 Myr (23.4-10.5)

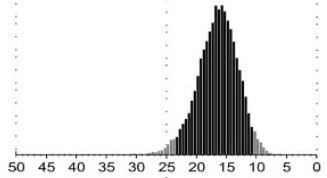

a: 32.9 Myr (42.9-23.6)

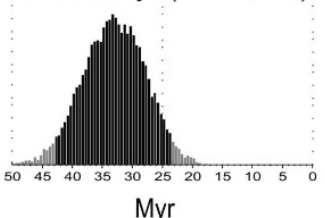

B

- Isolona hexaloba

Isolona congolana

Isolona congolana

Isolona pleurocarpa

Isolona pleurocarp
Isolona zenkeri (1)

Isolona zenkeri (2)

Isolona cooperi

Isolona campanulat

Isolona thonneri

Isolona dewevrei

Isolona cauliflora

Isolona heinsenii

Isolona linearis

Isolona capuronii

Isolona ghesquieri

Isolona perrieri

Monodora myristica (1)

Monodora myristica (1)

Monodora myristica (
Monodora undulata

Monodora laurentii

Monodora tenuifolia

Monodora crispata

Monodora angolensis

Monodora stenopetala

Monodora carolinae

Monodora globiflor

Monodora junodii

Monodora hastipetala

Monodora hastip

Monodora minor

Monodora grandidieri

Uvariopsis vanderystii

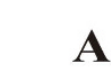

A
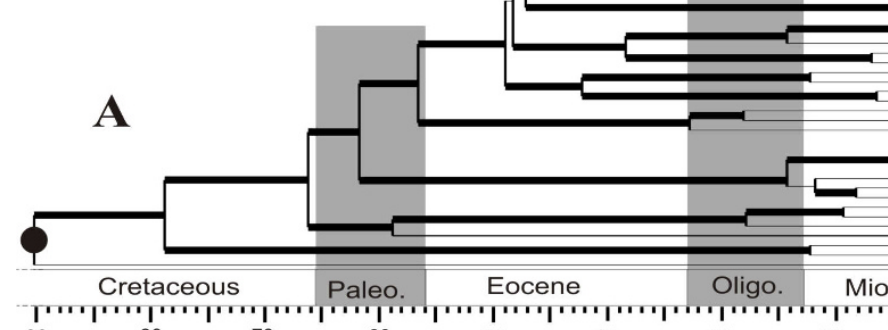

90

80

Figure 2

Estimated divergence times within African Annonaceae. Maximum clade credibility chronograms, with nodes represented by their mean ages estimated under a relaxed lognormal uncorrelated molecular clock assumption. East African endemic taxa are indicated in blue, West and Central African taxa in red, taxa endemic to Madagascar in black. Solid circles indicate nodes used for calibration of the trees. Open circles indicate nodes for which divergence dates were estimated. Thick branches lead to nodes with more than 0.95 posterior probability support. Geological Epochs, shaded bars: Paleo., Paleocene; Oligo., Oligocene; Pli., Pliocene; Pleis., Pleistocene. (A) Genus-level chronogram showing phylogenetic relationships within the African clade. (B) Species-level chronogram of the two sister genera Isolona and Monodora. (C) posterior distributions of the estimated ages. The $95 \%$ highest posterior density (HPD) intervals are indicated with black bars and given between brackets after the mean. These distributions were used to accept or reject significant congruence of node ages. 
nection-isolation events between the East African and Guineo-Congolian forests. Our results were obtained with just one plant group, but the biogeographic patterns observed in Annonaceae are common amongst many other tree families in Africa in terms of ecology (taxa restricted to rain forests) and distribution (disjunct between West/Central and East Africa) $[8,11,12]$. Therefore, we predict that the evolutionary process of divergence by vicariance on multiple occasions could be a common pattern for numerous other plant taxa in Africa, thus explaining much of the plant distribution and endemicity within African rain forest tree families. Interestingly, multiple splits between East and West-Central rain forest dwelling lineages at different times were also found to have occurred in African caecilian amphibians [48]. Thus, it would appear that this process could also be the main factor behind present day distribution patterns for a wide range of African rain forest restricted organisms, including animals.

Our results also provide important insights into the absolute time scale of these events, especially for the origin of the East African endemic lineages. The dates inferred from our study were obtained based on time calibration using the fossil taxon Archaeanthus (see Methods) as it is generally accepted to represent a minimum age constraint for the stem of Magnoliaceae [24,49,50,53,58,59]. Even acknowledging the complex history of vegetation change in East Africa [16] and the uncertainty in age estimates, the estimated origins of these splits using the Archaeanthus fossil calibration coincide well with known periods of renewed aridity and/or continental uplift in East Africa. These phenomena are generally thought to have played a role in the break-up of the pan-African rain forest, thus providing an explanation for the observed splits, which can be looked upon as further support of their correctness. The first split is dated to the Oligocene (mean: $32.9 \mathrm{Myr}$; Figure $2 \mathrm{~A}-\mathrm{a}$ ), which corresponds to a period of drastic global cooling resulting, in part, from the development of permanent continental ice-sheets in Antarctica [68]. This cooling induced a drier climate at equatorial levels in Africa, fragmenting the pan-African Eocene rain forest [14]. The second split, dated to the Late-Early Miocene (mean: 16.8, Figure 2A - b), post-dates an Early Miocene warmer and moister climate during which rain forest is thought to have extended again from coast to coast $[13,15]$, and coincides with the Miocene climatic optimum (17-15 Myr) characterized by high global temperatures [68]. This period also witnessed the closure of the Tethys sea when the African plate collided with the Eurasian one (c. 18-17 Myr), bringing an end to the moist influence of the latitudinal oceanic circulation system $[15,69]$. These drier conditions, as well as higher global temperatures, induced a new period of marked aridity, allowing the spread of savannas at the expense of rain for- ests $[15,69]$. This is visible at the paleobotanical level by an increase in grass abundance across Africa by $16 \mathrm{Myr}$ [16]. The third significant split (mean: 8.4-5.4 Myr) occurred in three lineages, Uvariodendron (Figure $2 \mathrm{~A}-\mathrm{c}$ ), Monodora (Figure 2B - d), and Isolona (Figure 2B - e), and took place after the initiation of geological activity in the western East African Rift System that uplifted the central Tanganyikan plateau (c. 10 Myr) [12,70]. Such uplifting has been shown to have played a significant role in the aridification of eastern Africa [70]. Moreover, this estimated date also coincides with a period of significant extension of savannas in East Africa $[16,69]$, as judged by an increase in biomass of plants using $\mathrm{C}_{4}$ photosynthetic pathways (8-6 Myr) [71].

Furthermore, even with our fossil-based minimum age estimates most speciation events in East African Isolona and Monodora (Figure 2B) have a pre-Pleistocene origin indicating a lack of diversification in the East African rain forests during the climatic fluctuations of the Pleistocene (e.g. [72]). For East Africa, this pattern was also documented in clawed frogs where all extant East African taxa were found to have originated before the Pleistocene [73]. Paleoecological records from the Eastern Arcs in Tanzania spanning the last 38,000 years provided evidence of ecosystem stability during the last glacial maximum period [74]. This lack of diversification during the Pleistocene is generally thought to be due to the stabilizing moist influence of the Indian Ocean on tropical rain forests in parts of coastal and montane East Africa, allowing them to persist throughout glacial periods without any important fluctuations in size $[12,75]$. Therefore, our results provide strong evidence that a larger Oligocene-Miocene continental-scale fragmentation between, rather than within, East and West-Central rain forest regions has played a major role in generating the patterns in plant distribution and endemicity that are currently observed across Africa. However, it may be that other, possibly herbaceous, groups diversified in East Africa as a result of Pleistocene climatic change but this is certainly not the case for Annonaceae and is likely also not true for other woody representatives of the East African rain forest flora.

Finally, our results indicate that the highly fragmented and threatened rain forests of Eastern Africa contain large amounts of pre-Pleistocene derived endemic lineages having evolutionary histories that date back to the Early Oligocene. A large majority of these lineages are species-poor [11], making them vulnerable to extinction. Additionally, most of the endemic species or genera are highly vulnerable to extinction because of small distributional ranges [9]. Subsequently, they have been red-listed with some level of threat to their survival (an estimated 22-25\% of the total number of endemic species [Roy Gereau, personal communication]). Thus, because of their ancient 
origins and species-poor composition, the extinction of just a handful of species could result in the loss of significant phylogenetic diversity [6]. This information should be carefully and urgently taken into consideration in future conservation planning within the East African region as knowledge of the presence of such ancient lineages allows us to prioritize areas with high phylogenetic diversity $[6,76,77]$.

\section{Conclusion}

Our molecular phylogenetic study on the evolutionary history of this pan-African Annonaceae rain forest clade provided numerous important insights into the evolutionary origins of African rain forest trees. We show that the East African lineages within this large clade have significantly different temporal origins. This would suggest that present day distribution and endemicity in African rain forest is a likely consequence of a series of connection-isolation events between the East African and Guineo-Congolian forests. Moreover, all the East African taxa appear to have diversified before the Pleistocene climatic oscillations. This provides evidence for the increasingly probable hypothesis that East African rain forests have been ecologically stable during those times. Finally, the old pre-Pleistocene origins of the endemic East African taxa suggest that these biodiversity hotspot regions contain high levels of phylogenetic diversity, an important factor to take into account for conservation priorities.

\section{Abbreviations}

Myr: million years; $P P$ : Bayesian posterior probability; HPD: highest posterior distributions.

\section{Authors' contributions}

TLPC carried out the molecular genetic studies, the sequence alignment, phylogenetic and dating analysis, and drafted the manuscript. LWC participated in the sequence alignment, supervised the study and helped to draft the manuscript. MSM participated in the design of the study. JER conceived the study, and participated in its design and coordination, and helped to draft the manuscript. All authors critically read and improved earlier drafts and approved the final manuscript.

\section{Additional material}

\section{Additional file 1}

Vouchers and genebank info. Taxon sampling, voucher information and GenBank accession numbers for each of the six (dataset A) and five (dataset B) chloroplast markers used in this study. UUCB: University Utrecht Botanical Garden; DRC: Democratic Republic of Congo.

Click here for file

[http://www.biomedcentral.com/content/supplementary/17417007-6-54-S1.xls]

\section{Acknowledgements}

We thank JJ Wieringa, BF Jacobs, JC Lovett, Q Luke, DJ Harris, E Haston, RT Pennington, and T van der Niet for useful comments and discussions. We also acknowledge A Robertson, D Johnson, and the Missouri Botanical Garden for providing plant DNA material. We are grateful to FM Mbago, RE Gereau, L Ngok Balak, Y Issembe, R Niangadouma, and M Botermans for their excellent help and assistance in the field. The governmental authorities of Gabon and Tanzania (COSTECH) as well as national park directors are thanked for granting collection permits. Funding for fieldwork came from the Netherlands Organization for Scientific Research (NWO), National Geographic Society, Alberta Mennega Stichting, Hugo de Vries Fonds, and Air France-KLM.

\section{References}

I. Hubbell SP: A unified theory of biogeography and relative species abundance and its application to tropical rain forests and coral reefs. Coral Reefs 1997, 16:S9-S21.

2. Molino JF, Sabatier D: Tree diversity in tropical rain forests: $\mathbf{A}$ validation of the intermediate disturbance hypothesis. Science 200I, 294: I702-I704.

3. Wills C, Harms KE, Condit R, King D, Thompson J, He F, MullerLandau HC, Ashton P, Losos E, Comita L, Hubbell S, LaFrankie J, Bunyavejchewin S, Dattaraja HS, Davies S, Esufali S, Foster R, Gunatilleke N, Gunatilleke S, Hall P, Itoh A, John R, Kiratiprayoon S, Loo de Lao S, Massa M, Nath C, Supardi Noor MN, Rahman Kassim A, Sukumar R, Suresh HS, Sun I, Tan S, Yamakura T, Zimmerman J: Nonrandom processes maintain diversity in tropical forests. Science 2006 , 3 I I:527-53I.

4. Moritz C, Patton JL, Schneider CJ, Smith TB: Diversification of rainforest faunas: An integrated molecular approach. Annu Rev Ecol Syst 2000, 3 I:533-563.

5. Pennington RT, Richardson JE, Lavin M: Insights into the historical construction of species-rich biomes from dated plant phylogenies, neutral ecological theory and phylogenetic community structure. New Phytol 2006, I 72:605-616.

6. Mace GM, Gittleman JL, Purvis A: Preserving the Tree of Life. Science 2003, 300:1707-1709.

7. Myers N, Mittermeier RA, Mittermeier CG, da Fonseca GAB, Kent J: Biodiversity hotspots for conservation priorities. Nature 2000, 403:853-858.

8. White F: The Guineo-Congolian region and its relationships to other phytochoria. Bull Jard Bot Nat Belg 1979, 49: I I-55.

9. Burgess ND, Clarke GP, Rodgers WA: Coastal forests of eastern Africa: status, endemism patterns and their potential causes. Biol J Linn Soc Lond 1998, 64:337.

10. Burgess ND, Butynski TM, Cordeiro NJ, Doggart NH, Fjeldså J, Howell KM, Kilahama FB, Loader SP, Lovett JC, Mbilinyi B, Menegon M, Moyer DC, Nashanda E, Perkin A, Rovero F, Stanley WT, Stuart SN: The biological importance of the Eastern Arc Mountains of Tanzania and Kenya. Biol Conserv 2007, 134:209-23I.

II. Burgess ND, Clarke GP: Coastal Forests of Eastern Africa Gland: IUCN: 2000.

12. Wasser SK, Lovett JC: Biogeography and Ecology of the Rainforests of Eastern Africa Cambridge: Cambridge University Press; 1993.

13. Morley RJ: Origin and Evolution of Tropical Rain Forests New York: John Wiley \& Sons; 2000.

14. Coetzee JA: African flora since the terminal Jurassic. In Biological relationships between Africa and South America Edited by: Goldblatt P. New Haven: Yale University Press; 1993:37-61.

15. Axelrod DI, Raven PH: Late Cretaceous and Tertiary vegetation history of Africa. In Biogeography and Ecology of Southern Africa Edited by: Werger MJA. The Hague: W Junk bv Publishers; 1978:77-130.

16. Jacobs BF, Kingston JD, Jacobs LL: The origin of grass-dominated ecosystems. Ann Missouri Bot Gard 1999, 86:590-643.

17. Davis CC, Bell CD, Fritsch PW, Mathews S: Phylogeny of Acridocarpus-Brachylophon (Malpighiaceae): implications for tertiary tropical floras and Afroasian biogeography. Evolution 2002, 56:2395-2405.

18. Couvreur TLP, Richardson JE, Sosef MSM, Erkens RHJ, Chatrou LW: Evolution of syncarpy and other morphological characters in African Annonaceae: a posterior mapping approach. Mol Phylogenet Evol 2008, 47:302-318. 
19. Punyasena SW, Eshel G, McElwain JC: The influence of climate on the spatial patterning of Neotropical plant families. J Biogeogr 2008, 35: I I7-130.

20. Couvreur TLP, Gereau RE, Wieringa JJ, Richardson JE: Description of four new species of Monodora and Isolona (Annonaceae) from Tanzania and an overview of Tanzanian Annonaceae diversity. Adansonia (Paris) 2006, 28:243-266.

21. Rogers ME, Abernethy K, Bermejo M, Cipolletta C, Doran D, McFarland K, Nishihara T, Remis M, Tutin CEG: Western gorilla diet: A synthesis from six sites. Am J Primatol 2004, 64:173-192.

22. Gentry A: Diversity and floristic composition of lowland tropical forest in Africa and South America. In Biological Relationships between Africa and South America Edited by: Goldblatt P. New Haven: Yale University Press; 1993:500-547.

23. Couvreur TLP: Monograph of the syncarpous African genera Isolona and Monodora (Annonaceae). Syst Bot Monogr in press.

24. Richardson JE, Chatrou LW, Mols JB, Erkens RHJ, Pirie MD: Histor ical biogeography of two cosmopolitan families of flowering plants: Annonaceae and Rhamnaceae. Philos Trans $R$ Soc Lond $B$ Biol Sci 2004, 359: |495-1508.

25. Qiu YL, Lee J, Bernasconi-Quadroni F, Soltis DE, Soltis PS, Zanis M Zimmer EA, Chen Z, Savolainen V, Chase MW: Phylogeny of basa angiosperms: Analyses of five genes from three genomes. Int J Plant Sci 2000, I 6 I:S3-S27.

26. Sauquet H, Doyle JA, Scharaschkin T, Borsch T, Hilu KW, Chatrou LW, Le Thomas A: Phylogenetic analysis of Magnoliales and Myristicaceae based on multiple data sets: implications for character evolution. Bot J Linn Soc 2003, I 42: I 25-I86.

27. Doyle J], Doyle JL: A rapid DNA isolation procedure from small quantities of fresh leaf tissue. Phyt Bull 1987, I9: I I- I5.

28. Bakker FT, Hellbriigge D, Culham A, Gibby M: Phylogenetic relationships within Pelargonium sect. Peristera (Geraniaceae) inferred from nrDNA and cpDNA sequence comparisons. Plant Syst Evol 1998, 21 I:273-287.

29. Taberlet P, Gielly L, Pautou G, Bouvet J: Universal primers for amplification of 3 noncoding regions of chloroplast DNA Plant Mol Biol 1991, I 7:1 105-II09.

30. Hamilton MB: Four primer pairs for the amplification of chloroplast intergenic regions with intraspecific variation. Mol Ecol 1999, 8:52I-523.

31. Shaw J, Lickey EB, Beck JT, Farmer SB, Liu W, Miller J, Siripun KC, Winder CT, Schilling EE, Small RL: The tortoise and the hare II: relative utility of 21 noncoding chloroplast DNA sequences for phylogenetic analysis. Am J Bot 2005, 92: I 42-I66.

32. Erkens RHJ, Chatrou LW, Maas JW, Pirie MD: Phylogenetic relationships, saturation and marker-use in the Long Branch Clade of Annonaceae. In PhD thesis, From morphological nightmare to molecular conundrum. Phylogenetic, evolutionary and taxonomic studies on Guatteria (Annonaceae) Edited by: Erkens RHJ. Utrecht University, Utrecht; 2007:25-4I.

33. Olmstead RG, Sweere JA: Combining data in phylogenetic systematics: an empirical approach using three molecular data sets in the Solanaceae. Syst Biol 1994, 43:467-48I.

34. Staden Package WWW site [http://staden.sourceforge.net]

35. Swofford DL: PAUP* Phylogenetic Analysis Using Parsimony (* and other methods), v. 4.0 beta I0. Sunderland: Sinauer Associates; 2002

36. Simmons MP, Ochoterena $\mathrm{H}$ : Gaps as characters in sequencebased phylogenetic analyses. Syst Biol 2000, 49:369-38I.

37. Levinson G, Gutman G: Slipped-strand mispairing: a major mechanism for DNA sequence evolution. Mol Biol Evol 1987 4:203-221.

38. Drummond AJ, Ho SYW, Phillips MJ, Rambaut A: Relaxed phylogenetics and dating with confidence. PLOS Biol 2006, 4:699-7IO.

39. Drummond AJ, Rambaut A: BEAST: Bayesian evolutionary analysis by sampling trees. BMC Evol Biol 2007, 7:214

40. Ho SYW, Phillips MJ, Drummond AJ, Cooper A: Accuracy of rate estimation using relaxed-clock models with a critical focus on the early metazoan radiation. Mol Biol Evol 2005 22:1355-1363.

41. Sanderson M: A nonparametric approach to estimating divergence times in the absence of rate constancy. Mol Biol Evol |997, | 4:|2|8-|23|.

42. Thorne JL, Kishino H, Painter IS: Estimating the rate of evolution of the rate of molecular evolution. Mol Biol Evol 1998 , I 5:1647-1657.
43. Sanderson MJ: Estimating absolute rates of molecular evolution and divergence times: A penalized likelihood approach. Mol Biol Evol 2002, I 9: I01-109.

44. BEAST partitioning [http://tlpcouvreur.googlepages.com/beast partitioning]

45. Akaike $\mathrm{H}$ : Information theory as an extension of the maximum likelihood principle. In Second International Symposium on Information Theory Edited by: Petrov BN, Csaki F. Budapest: Akademiai Kiado; 1973:267-28I.

46. Nylander JAA: MrModeltest v2. In Program distributed by the author Uppsala: Evolutionary Biology Centre, Uppsala University; 2004.

47. Rambaut A, Drummond AJ: Tracer. Version I.4. 2003 [http:// evolve.zoo.ox.ac.uk/]

48. Loader SP, Pisani D, Cotton JA, Gower DJ, Day JJ, Wilkinson M: Relative time scales reveal multiple origins of parallel disjunct distributions of African caecilian amphibians. Biol Lett 2007, 3:505-508.

49. Dilcher DL, Crane PR: Archaeanthus - an early angiosperm from the Cenomanian of the western interior of NorthAmerica. Ann Missouri Bot Gard 1984, 7 I:35I-383.

50. Doyle JA, Sauquet H, Scharaschkin T, Le Thomas A: Phylogeny, molecular and fossil dating, and biogeographic history of Annonaceae and Myristicaceae (Magnoliales). Int J Plant Sci 2004, 165:S55-S67.

5I. Friis EM, Pedersen KR, Crane PR: Cretaceous anglosperin flowers: Innovation and evolution in plant reproduction. Palaeogeogr Palaeoclimatol Palaeoecol 2006, 232:25 I-293.

52. Crepet WL, Nixon KC, Gandolfo MA: Fossil evidence and phylogeny: The age of major angiosperm clades based on mesofossil and macrofossil evidence from cretaceous deposits. Am | Bot 2004, 91:1666-1682.

53. Pirie MD, Chatrou LW, Mols JB, Erkens RHJ, Oosterhof J: 'Andeancentred' genera in the short-branch clade of Annonaceae: testing biogeographical hypotheses using phylogeny reconstruction and molecular dating. J Biogeogr 2006, 33:31-46.

54. Chesters KIM: Some plant remains from the Upper Cretaceous and Tertiary of West Africa: Maastrichtian seeds of Annonaceae. Ann Mag Nat Hist Ser 1955, I 2:498-504.

55. Kvacek J, Eklund $\mathrm{H}$ : A report on newly recovered reproductive structures from the Cenomanian of Bohemia (Central Europe). Int J Plant Sci 2003, I 64: I 021 - 1039

56. Mohr BAR, Bernardes-de-Oliveira MEC: Endressinia brasiliana, a magnolialean angiosperm from the Lower Cretaceous Crato Formation (Brazil). Int J Plant Sci 2004, I 65: I I 2 I-I I 33.

57. Mohr BAR, Eklund $\mathrm{H}$ : Araripia florifera, a magnoliid angiosperm from the Lower Cretaceous Crato Formation (Brazil). Rev Palaeobot Palynol 2003, I 26:279-292.

58. Crepet WL: The fossil record of angiosperms: Requiem or renaissance? Ann Missouri Bot Gard 2008, 95:3-33.

59. Pirie MD: The age of clades in Annonaceae: progress in molecular dating. In The Natural History of the Annonaceae Edited by: Chatrou LW, Erkens RHJ, Richardson JE. Regnum Vegetabile in press.

60. Wikström N, Savolainen V, Chase MW: Evolution of the angiosperms: calibrating the family tree. Proc Biol Sci 200I, 268( | 482):22 | |-2220.

61. Zhou SL, Renner SS, Wen J: Molecular phylogeny and intra- and intercontinental biogeography of Calycanthaceae. Mol Phylogenet Evol 2006, 39: I-I5.

62. Berry PE, Hahn WJ, Sytsma KJ, Hall JC, Mast A: Phylogenetic relationships and biogeography of Fuchsia (Onagraceae) based on noncoding nuclear and chloroplast DNA data. Am J Bot 2004, $91: 601-614$

63. Renner SS: Relaxed molecular clocks for dating historical plant dispersal events. Trends Plant Sci 2005, 10:550-558.

64. Shaul S, Graur D: Playing chicken (Gallus gallus): methodological inconsistencies of molecular divergence date estimates due to secondary calibration points. Gene 2002, 300:59-61

65. Ho SYW: Calibrating molecular estimates of substitution rates and divergence times in birds. I Avian Biol 2007 38:409-4I4

66. Peng ZG, Ho SYW, Zhang YG, He SP: Uplift of the Tibetan plateau: Evidence from divergence times of glyptosternoid catfishes. Mol Phylogenet Evol 2006, 39:568-572. 
67. Sanderson MJ: r8s: inferring absolute rates of molecular evolution and divergence times in the absence of a molecular clock. Bioinformatics 2003, 19:301-302.

68. Zachos J, Pagani M, Sloan L, Thomas E, Billups K: Trends, rhythms, and aberrations in global climate $65 \mathrm{Ma}$ to present. Science 200I, 292:686-693.

69. Jacobs BF: Palaeobotanical studies from tropical Africa: relevance to the evolution of forest, woodland and savannah biomes. Philos Trans R Soc Lond B Biol Sci 2004, 359: I573-I583.

70. Sepulchre P, Ramstein G, Fluteau F, Schuster M, Tiercelin J], Brunet $\mathrm{M}$ : Tectonic uplift and Eastern Africa aridification. Science 2006, 313:1419-1423

7I. Cerling TE, Harris JM, MacFadden BJ, Leakey MG, Quade J, Eisenmann $\mathrm{V}$, Ehleringer JR: Global vegetation change through the Miocene/Pliocene boundary. Nature 1997, 389: I53-158.

72. Haffer J: Speciation in Amazonian forest birds. Science 1969, 165: I3I-|37.

73. Evans BJ, Kelley DB, Tinsley RC, Melnick DJ, Cannatella DC: A mitochondrial DNA phylogeny of African clawed frogs: phylogeography and implications for polyploid evolution. Mo Phylogenet Evol 2004, 33:197-213.

74. Mumbi CT, Marchant R, Hooghiemstra H, Wooller MJ: Late Quaternary vegetation reconstruction from the Eastern Arc Mountains, Tanzania. Quaternary Research 2008, 69:326-34I.

75. Marchant R, Mumbi C, Behera S, Yamagata T: The Indian Ocean dipole - the unsung driver of climatic variability in East Africa. Afr J Ecol 2007, 45:4-16.

76. Yamagata T, Balmford A, Manning JC, Proches S, Bank M van der Reeves G, Hedderson TAJ, Savolainen V: Preserving the evolutionary potential of floras in biodiversity hotspots. Nature 2007, 445:757-760.

77. Sechrest W, Brooks TM, da Fonseca GAB, Konstant WR, Mittermeier RA, Purvis A, Rylands AB, Gittleman JL: Hotspots and the conservation of evolutionary history. Proc Natl Acad Sci USA 2002, 99:2067-2071.
Publish with Bio Med Central and every scientist can read your work free of charge

"BioMed Central will be the most significant development for disseminating the results of biomedical research in our lifetime. "

Sir Paul Nurse, Cancer Research UK

Your research papers will be:

- available free of charge to the entire biomedical community

- peer reviewed and published immediately upon acceptance

- cited in PubMed and archived on PubMed Central

- yours - you keep the copyright 